\title{
la práctica artística como alegoría de la investigación Artes y Humanidades: una cuestión de formas (de hacer)
}

CORNAGO, Oscar.*

Consejo Superior de Investigaciones Científicas - Madrid

Resumen:

La introducción de la enseñanza de las artes en los ciclos superiores de máster y doctorado ha renovado el debate sobre las relaciones entre artes y ciencias. Este artículo analiza las implicaciones de este conflicto reformulado ahora en términos de prácticas (artísticas) frente a investigación (teórica). Dentro del contexto del nacimiento de la subjetividad moderna y las Humanidades, tal y como lo expone Foucault, revisa la idea de praxis ligada a los campos de la naturaleza, el trabajo y la política, apoyándose en Hannah Arendt, Giorgio Agamben y Paolo Virno entre otros pensadores.

Palabras clave:

Teoría del arte, teoría de la acción, historia de la ciencia, Modernidad.

\section{Abstract}

The introduction of arts education in the upper cycles Masters and $P h D$ has renewed a debate about the relationship between arts and sciences. This article discusses the implications of this conflict now reformulated in terms of practice (art) versus research (theoretical). Within the context of the birth of modern subjectivity and the Humanities, as Foucault puts it, reviews the idea of praxis related to the fields of nature, politics and work, drawing on Hannah Arendt, Giorgio Agamben and Paolo Virno among other thinkers.

Key words

Art theory, Performance theory, history of sciencie, Modernity.
Este trabajo se enmarca dentro del proyecto del Programa Nacional I + D del Ministerio de Ciencia e Innovación de España, "Imaginarios sociales en las culturas de la globalización: entre lo público y lo privado. Documentación y análisis de la creación escénica en Iberoamérica (2000-2010)" (HAR2008-06014-C02/ ARTE). 
El arte y la ciencia comparten una misma y sospechosa tendencia a la universalidad, aunque desde presupuestos distintos: la universalidad del espíritu y la universalidad del conocimiento. Sin embargo, a ambos, artistas y científicos, les ha tocado bajar del olimpo, les ha tocado aproximarse a su público, convertido cada vez más en una suerte de consumidores; acortar las distancias, al menos aparentemente, porque es lo que marcan los tiempos, hacer si no al servicio, sí en relación -y mientras más próxima mejor-con aquellos que están en frente o alrededor, porque esa situación es la que termina dando el sentido a lo que hacen, una situación en tiempo presente. De este modo, creación artística y investigación científica han ido dejando ver cada vez de forma más clara el presente desde el que se construyen, las contingencias de un modo de producción, que es también un manera de hacer.

En la evolución de los modos de legitimar la democracia, o en otras palabras, los modos de legitimiar el funcionamiento de la representación política, Pierre Ronsanvallon ${ }^{1}$ se refiere a la proximidad como estrategia de poder dentro del juego político actual, y analiza la idea de proximidad en tres aspectos, cercanía espacial, interactividad y participación. No resulta difícil identificar estos aspectos en el campo de las prácticas artísticas y las formas de plantear el trabajo en ciencias, dos campos no en vano relacionados con las formas de representación.

Dentro de esta dinámica de "proximidades" que se ha venido conformando a lo largo del último tercio del siglo $\mathrm{XX}$, y que ha afectado tanto al desarrollo de las Humanidades y las Ciencias Sociales como de la producción estética, el artista y el científico están llamados a encontrarse en un espacio institucional en el que tradicionalmente el artista, como sujeto de creación, era una rareza de laboratorio. Este nuevo escenario de operaciones cuestiona, una vez más en esta historia de cuestionamientos que es la modernidad, la posibilidad del juicio artístico, basado en la distancia de la percepción, sobre la que se construye el edificio de la estética, como la posibilidad de la transmisión del conocimiento. Dicho de otro modo, la pregunta que este desplazamiento plantea es la de un arte sin espectador o una ciencia sin destinatario, en ambos casos el problema tiene que ver con la consideración del arte o de la ciencia como una forma no de acción, sino de representación. Ante este callejón sin salida que afecta al sentido de las representaciones, artísticas o científicas, el mundo académico se abre al arte no en primer lugar como forma de representación, sino como práctica o forma de actuación, como manera de estar y pensar, en paralelo a otras tendencias culturales que han focalizado la idea de "acción" como estrategia para situarse frente a la realidad.
1.

Pierre Rosanvallon, La legitimidad democrática. Imparcialidad, reflexividad, proximidad, Buenos Aires, Manantial, 2009. 
La introducción de las artes en los grados superiores de enseñanza, de máster y doctorado, ha reanimado un viejo debate entre el ámbito científico y el artístico, aunque con una formulación y una necesidad nuevas. ${ }^{2}$ La necesidad de homologar qué es lo que puede ser considerado investigación en artes, cómo determinar una forma de trabajar "científicamente" con instrumentos artísticos, ha conducido este debate a un campo institucional, donde una vez más se han puesto de manifiesto límites y contradicciones que más allá del ámbito específico del arte o de la ciencia atraviesan y conforman la cultura moderna. El debate viene, por tanto, de atrás, aunque en cada momento se ha planteado desde espacios y con intereses distintos.

Tradicionalmente la enseñanza de las artes ha estado en manos de escuelas técnicas o conservatorios, donde se proporcionaba a los aspirantes a artistas el conocimiento de una serie de materiales, técnicas de composición, modos de expresión, corrientes históricas y formas de comunicación, todo ello orientado a una formación de carácter práctico que tenía como objetivo el dominio en el manejo de unos determinados materiales entendidos como instrumentos de expresión: el color, los sonidos, las palabras, el cuerpo, la voz o la imagen. La ampliación de la formación artística a los ciclos superiores, de forma paralela a otras disciplinas universitarias, ha puesto sobre la mesa el debate de la investigación también en este campo, lo que ha vuelto a destapar esta vieja caja de Pandora. Lo más significativo de este último capítulo de la historia de Occidente, considerando este conflicto como un síntoma cultural, es que su escenario se haya trasladado a la esfera institucional, es decir, que las propias instituciones, conservadoras por definición, hayan tenido que abrirse a este juego de tensiones resultado de la confrontación entre el fenómeno artístico y las disciplinas de conocimiento delimitadas oficialmente desde esas mismas instituciones. Este nuevo espacio de diálogo entre arte e investigación puede ser estudiado como una consecuencia tanto de ciertas tendencias artísticas consolidadas en el último tercio del siglo XX como de nuevos planteamientos en la investigación y los modos de producción del conocimiento.

La primera pregunta que podría plantearse, antes incluso de entrar en las posiciones del debate, es el por qué se ha llegado a este punto, cuál es el interés de homologar las enseñanzas artísticas integrándolas en el sistema universitario, al margen de los beneficios pragmáticos que se derivan del acceso para la creación artística a otro tipo de recursos económicos destinados a la investigación y difusión del conocimiento; dicho de
2.

Para un estado de la cuestión véase el monográfico incluido en Cairón, 13 (2010) coordinado por Victoria Pérez Royo y José Antonio Sánchez, en especial el estudio de Henk Borgdorff, "The debate on research in the arts", que puede encontrarse también en la página de la Amsterdamse Hogeschool voor de kunsten (http:// www.ahk.nl/fileadmin/download/ ahk/Lectoraten/ Borgdorff_publicaties/ The_debate_on_research_in_the_arts.pdf), y el informe de Pérez Royo, "El perfil investigador-creador en los estudios de posgrado en artes escénicas", Cairón 13 (2010), pp. 125-138. 
otro modo, qué es lo que las artes pueden aportar al conocimiento y por tanto a la sociedad, porque una institución como la universitaria se entiende que tiene su razón de ser en función de unas necesidades sociales; y viceversa, qué es lo que la investigación científica y la idea del conocimiento pueden aportar a la práctica de las artes. Este intento por buscar una rentabilidad social a las prácticas artística, definidas en la tradición estética occidental por su "gratuidad" o su aparente desinterés con respecto a la rentabilización de los resultados una visión que nace con el Romanticismo y que se ha intentado dar por acabada en tantas ocasiones ya desde el siglo XIX-, tampoco es nueva, aunque lo llamativo es que ahora la iniciativa parta, no de espacios artísticos o sociales independientes, sino de las propias instituciones oficiales donde se delimita lo que es conocimiento y las formas de producirlo y divulgarlo.

La polémica en todo caso está servida desde el momento en que conocimiento científico y creación artística tomaron vías divergentes para ocuparse de ámbitos distintos; desde ese tiempo ya lejano la discusión sobre sus diferencias y especicificidades, así como la necesidad del diálogo entre uno y otro, son temas que se han ido planteando de diverso modo y con especial intensidad en algunos momentos del siglo XX en los que se creyó más de cerca en esa utópica confluencia entre ciencia y arte. Este nuevo debate, reformulado ahora con menos idealismo y más concreción, puede considerarse el penúltimo capítulo de una historia fundacional de la Modernidad que es la historia de una escisión no reconocida entre subjetividad y conocimiento, o experiencia y saber científico, o individuo y esfera pública, un acto de mala fe ontológica, podríamos decir, tomando prestada la expresión que Paul de $\mathrm{Man}^{3}$ utiliza para calificar la sustitución a comienzos del siglo XIX del término alegoría por el de símbolo. Paul de Man identifica esta operación como una estrategia para entender el mundo, o el arte, en tanto que proyección de una subjetividad, de una voluntad creadora, pero también de poder. Porque en el fondo se trataba de eso, de apropiarse de lo que se resistía al conocimiento o a la representación, una técnica de conquistadores dirá ya en los años setenta Lyotard pensando en la semiótica, ${ }^{4}$ que no por azar fue el método que terminó de consolidar el rango de "ciencia" en las Humanidades, cuando la consideración cientificista de este grupo de disciplinas era algo todavía sujeto a discusión. Al final es un problema de método, que es lo que ahora se vuelve a plantear para el trabajo artístico, la necesidad de una formalización del proceso de creación que transforme el hacer práctico en una forma de interrogación y búsqueda de nuevas respuestas, de modo que pueda ser enseñada y rentabilizada socialmente.
3.

Paul de Man, "Retórica de la temporalidad", en Visión y ceguera. Ensayos sobre la retórica de la crítica contemporánea, Río Piedras, Universidad de Puerto Rico, 1991, pp. 207-253.

4.

"El signo va con ese viaje de negocios, y el viaje de negocios crea el signo: ¿qué es un africano para un explorador británico? ¿Qué es un japonés para un jesuita del siglo XVIII? Órganos y pulsiones parciales que serán reabsorbidos en el cuerpo normal orgánico único llamado Humanidad o Creación. Materiales para desmaterializar y hacer significar. Nosotros, semiólogos, jesuitas, Stanleys, conquistadores, sólo habremos hecho una conquista cuando tengamos ese código y podamos rehacerlo, simularlo.”, Jean-François Lyotard, Economía libidinal, Madrid, Fundamentos, 1991, p. 55. 
Aunque dentro del tándem ciencia-conocimiento, el primer elemento, como mero instrumento para llegar al segundo, puede parecer más libre de intereses espúreos, es decir, de contingencias externas o contextos políticos, lo cierto es que la ciencia también tiene una historia - como veremos a continuación- y esa historia está ligada a lo que en cada momento se ha considerado que era "conocimiento", un campo cuya determinación viene unida a las formas de configurar el poder, como apuntaban Paul de Man o Lyotard, y el poder es antes que nada una cuestión de praxis, una forma de hacer. En este sentido, Michel de Certeau, aún aceptando la legitimidad de entender - de un modo idealista, podríamos añadir- el poder del conocimiento como la "capacidad de transformar las incertidumbres de la historia en espacios legibles", añade que es más exacto reconocer el poder como la "condición previa del conocimiento, y no sólo su efecto o atributo". ${ }^{5}$

A pesar de esa marcada vocación universalista, ambos fenómenos están datados, por tanto, históricamente, y cualquier respuesta acerca del posible diálogo o complementación o antagonismo entre ambos debe estar referida a un momento determinado de esa historia. La manera de entender lo que es ciencia, lo que se considera conocimiento y las formas de llegar hasta él y difundirlo han ido cambiando al mismo tiempo que han cambiado también los modos de entender el hecho artístico y sus formas de producción y comunicación. Y uno y otro campo, ciencia y arte, están vinculados al fin y al cabo con dos grandes espacios, conocimiento y producción de la subjetividad, sobre los que se legitiman las formas de poder. Si a finales del siglo XX una institución característica de la sociedad del saber y el bienestar como la universidad ha tenido la necesidad de reconciliar nuevamente estos dos campos, es porque algo está ocurriendo o ha estado ocurriendo hasta alcanzar la suficiente fuerza como para transformar estructuras tan conversadoras y dependientes de la vida política como las universidades.

En un libro que tiene como subtítulo "Destrucción de la experiencia y origen de la Historia", Giorgio Agamben ${ }^{6}$ plantea un recorrido en paralelo de estos dos campos. Para ello se remonta a una época previa a la construcción de esta Historia moderna, un momento en el que todavía no estaba formada ni la idea de la subjetividad ni la de ciencia tal y como hoy las entendemos. Para la Edad Media Agamben distingue dos ámbitos que remiten a realidades distintas, el del conocimiento y el de lo que hoy llamaríamos subjetividad, que entonces correspondía a la idea del sentido común, construido a partir de la experiencia personal. El primero de estos campos, el conocimiento, que determina los modelos científicos, no tenía que
5.

Michel de Certeau, La invención de lo cotidiano I. Artes de hacer, México, Universidad Iberoamericana, 2007, p. 43. La cursiva es del original.
6. Giorgio Agambem, Infancia e historia. Destrucción de la experiencia y origen de la historia, 2 ed., Buenos Aires, Adriana Hidalgo, 2004. 
ver con el individuo, sino con la revelación de una verdad superior. El agente de esa verdad era un "nosotros" cercano a lo religioso, una entidad impasible y divina, de ahí que ciencias como la astrología estuvieran relacionadas con la magia o lo sagrado, vecinas también a la mística o la alquimia, y de ahí también que las ciencias entonces estuvieran ligadas a una práctica, un hacer o una actitud, una dimensión performativa del conocimiento que luega va a ser heredada por las artes, mientras que las ciencias, a pesar de que en muchos casos se apoyen en prácticas de laboratorio o estudios de campo, se vincularán con la idea de la observación, especulación, discurso abstracto y reflexión teórica, dentro de un proceso que podríamos denominar como desmaterialización de la ciencia.

Con el desarrollo de la subjetividad se crea un yo que va a pasar a ser el nuevo sujeto del conocimiento, de ese conocimiento teórico ligado a lo científico, es decir, a una actividad mental, un yo pienso que inicialmente, como dice Agamben, es tan sólo el sujeto gramatical de un verbo de escasa sustancia espiritual. Esta operación gramatical permite vincular el proceso del conocimiento al individuo, creando un arco teórico que iría desde la experiencia personal al saber científico. El yo-pienso se coloca como garantía de un saber, que ya no va a bajar del cielo, ni va a estar relacionado con la idea de la revelación, sino que se va a desarrollar desde metodologías empíricas, una verdad con apariencia de objetividad pero que tiene que nacer, sin embargo, del individuo para proyectarse desde ahí hacia fuera (como decía Paul de Man refiriéndose a la experiencia estética relativa al símbolo). Mientras que lo más cercano a esa idea de "revelación" quedará en el campo de las artes en forma de inspiración, lo demás a partir de ahora será resultado del trabajo intelectual que trata de medir, ordenar, clasificar y comparar para llegar al conocimiento. El yo queda atrapado como base de un conocimiento científico y la experiencia, que convive con lo incierto, lo cambiante, lo que no se puede medir, va a dar lugar al arte como expresión de una imposibilidad, de un sujeto que ya no es sujeto de nada más que de un mundo interior y ajeno. A cambio, el conocimiento científico va a quedar respaldado, pero sólo en teoría, por el individuo como sujeto de una experiencia que es principio del saber. "En su búsqueda de la certeza -explica Agamben-, J la ciencia moderna anula esa separación y hace de la experiencia el lugar - el "método", es decir, el caminodel conocimiento". De esta manera, algo tan pragmático como Agamben, Infanciae historia, p. 18. el conocimiento o los campos de saber, a pesar de tener como principio al sujeto investigador, un yo-pienso, adopta la apariencia de un trabajo teórico liberado de toda contingencia y más allá de intereses materiales. El conocimiento se desmate- 
rializa. La singularidad del sujeto se proyecta a través de una operación intelectual al plano de lo universal, y el individuo, el espacio de la experiencia y lo sensible, queda en función de una verdad abstracta, eliminando la posibilidad de la no certeza, de la contradicción y lo efímero, es decir, lo que no se deja representar, como base del conocimiento. La otra posibilidad de expresión de ese límite será la religión —relegada, como el arte, a los márgenes del espacio oficial de conocimientocomo afirmación a través de una práctica que actualiza la fe de un yo sujeto, ahora sí, a una fuerza trascendental.

Si tenemos que hacer balance de esta primera negociación entre arte y ciencia, diríamos que la ciencia es reconocida como un tipo de trabajo teórico, de rango superior, al que se le supone una productividad social, y el arte queda como una concesión al bando perdedor a cambio de la expropiación del sujeto al servicio de la construcción del edificio de la ciencia. Ciencia y arte pasan ya en la Enciclopedia de Diderot como campos ligados a la especulación, en el primer caso, y a la ejecución, en el segundo. Entre estos dos polos se abre un espacio intermedio que será ocupado por las Humanidades, a las que se unirán a lo largo del siglo XIX y XX las Ciencias Sociales. Las llamadas Ciencias Humanas, a mitad de camino entre la objetividad cientificista y la subjetividad parcialmente emancipada, no dejarán de ser miradas con cierta condescendencia cuando no con recelo.

En Las palabras y las cosas Foucault ${ }^{8}$ se remonta también a este momento de transición de la época clásica a la moderna para analizar, a partir de un recorrido por la historia de las ciencias, el nacimiento de las Humanidades, que no por azar se produce en paralelo al fenómeno artístico. Ambos, el nacimiento de las Humanidades y el del arte, son resultado de lo que el pensador francés explica como la fragmentación de la mathesis universalis, un sistema único de ordenación y medida que organiza toda la realidad. Las ciencias antiguas funcionaban a través de este sistema de representación dispuesto en forma de listados abiertos de los elementos que se encontraban en la realidad. La gramática listaba las partes de la oración, la anatomía las partes del cuerpo y los estudios de la riqueza las propiedades de la Iglesia, las casas feudales y los comerciantes. Con la fractura de este sistema único de representación, cada campo de conocimiento se va a replegar sobre sí mismo, pasando a funcionar no ya como listados, sino como sistemas articulados, interdependientes, pero autónomos. De este modo, la Gramática se transforma en Filología, que se organiza a partir de las funciones de cada parte de la oración, la Anatomía da lugar a la Biología, que se ocupa también de las funciones de cada parte del cuerpo, y de los Estudios de las
8.

Michel Foucault, Las palabras y las cosas. Una arqueología de las ciencias humanas, Madrid, Siglo Veintinuo, 1968. 
Riquezas pasan a ocuparse las Ciencias Económicas, con una visión más articulada que da cuenta de las transformaciones del capital y la idea de trabajo. El repliegue sobre sí mismo de estos sistemas deja unos espacios vacíos donde van a surgir las preguntas que van a dar lugar a las Humanidades, las preguntas por el motor de estas representaciones, por su modo de funcionamiento y el producto final, la idea de lenguaje, del hombre y de la vida, o del trabajo. Paralelamente surge la Estética, que se ocupa de los modos de percepción, y cuyo campo autónomo de pruebas será el Arte, un espacio que en la filosofía kantiana, uno de los exponentes por excelencia de este movimiento de desmaterialización, va a servir de puente entre la teoría del conocimiento y la práctica de la moral.

A pesar de este origen común, las Humanidades y las artes van a mirar en direcciones divergentes o al menos de modos distintos; las primeras van a luchar por legitimarse como espacio objetivo de conocimiento, tratando de asimilarse en sus formas de operar a las ciencias para adquirir así tal estatus -algo comparable a lo que podría estar ocurriendo hoy con las artes-, y estas a su vez van a buscar su legitimación como expresión de una subjetividad que había quedado huérfana al pasar a formar parte de esa aventura del yo pienso. De este modo las Humanidades van a tratar de desarrollar una metodología específica, importada inicialmente, sobre todo en el siglo XIX, de las ciencias naturales. Así se recurre primero al empirismo, el positivismo lógico y la denominada observación "científica" de la realidad. Más tarde la alternativa la darán la Antropología y las Ciencias Sociales, que quedaban más cerca de las Humanidades y que como ciencias jóvenes tomaron un rápido impulso y credibilidad, y finalmente en la búsqueda de una metodología propia, no importada, la tabla de salvación vendrá de la Lingüística y el estudio de los signos.

Es sobre todo en torno a los años setenta y ochenta cuando se trata de formalizar el análisis de los diversos campos artísticos (literatura, imagen, artes plásticas, cine, música o teatro) y por extensión, vía la semiótica, de otros campos culturales. Esta operación será posible gracias a la herencia de las diversas tradiciones formalistas que habían ido desarrollándose desde las primeras décadas de siglo, como las teorías de la Pura Visibilidad en artes visuales, la semiótica de Saussure, el funcionalismo norteamericano, el formalismo y la lingüística de las escuelas del Este, la Estilística y la evolución de algunas de estas corrientes ya en los sesenta a través del Posestructuralismo. Se consolida así un modo de trabajo en Humanidades y Ciencias Sociales que bajo el rótulo general de Estructuralismo Foucault definirá no como un método nuevo, sino como "la conciencia despierta e inquieta del saber 
moderno", 9 es decir, algo que está por detrás incluso del conocimiento, una metodología, una forma de operar o una actitud que lo hace posible, una maquinaria de enunciación que lo positiviza como espacio de conocimiento.

De este modo, el estudio de la cultura como sistema de signos, es decir, como tejido o texto, entendiendo este concepto en su sentido más abstracto, y forma de representación va a dar alas a las Humanidades al tiempo que produce un efecto de contaminación entre los diversos ámbitos de conocimiento. Resultado de este panorama serán fenómenos consolidados en el último tercio del siglo XX como los "estudios culturales" o el nacimiento del "performance" como instrumento de investigación en Humanidades y Ciencias Sociales. Producto de este movimiento de apertura y renovación es también la inclusión de las artes, no ya como objeto de estudio para el conocimiento de su práctica o de su historia, sino como prácticas específicas de investigación dentro del ámbito universitario.

Conviene detenerse en este momento, en el que a la vez que se desarrolla la semiótica como estación final de los formalismos comienza a apuntarse en el medio académico esta perspectiva performativa, que va a servir de relevo y nuevo motor en la investigación dentro de las Humanidades. Ambas aproximaciones no son excluyentes, pero definen modos de mirar y por tanto metodologías distintas; mientras que la primera, a través del estudio de los signos, se centra en la organización y resultado de las representaciones, ya no sólo artísticas sino también culturales en un sentido amplio, la segunda va a enfocar estas representaciones desde el punto de vista de sus formas de producción en tanto que prácticas sociales. Este enfoque performativo toca campos disciplinares bien diversos, pero una de sus piedras de toque va a ser en todo caso el espacio artístico como objeto de reflexión teórica. No es un azar que sea también a lo largo de los años sesenta y setenta cuando se consolide el performance como un género específico dentro de las artes.

Las primeras formulaciones de este debate se pueden rastrear también en tiempos remotos, cuando comienza la discusión sobre la naturaleza del arte. El mismo Agamben, que hace esa revisión de las ideas de ciencia y subjetividad, unos años antes dedica un estudio a la consideración del arte como práctica a lo largo de la tradición occidental, excusa que le valdrá para ir más allá de lo artístico. ${ }^{10}$ Partiendo de la diferenciación en la filosofía griega entre poiesis, como un modo de hacer que tenía que ver con la revelación de una verdad, es decir, con el conocimiento, con el hecho de traer a la luz un saber oculto, y praxis, como producción a través de la realización de una acción, y la posterior confusión entre ambos
9. Foucault, Las palabras y las cosas, p. 206.
10

Giorgio Agamben,

"Poiesis y praxis", en El hombre sin contenido, Barcelona, Áltera, 2005, pp. 111-154. 
conceptos en la tradición latina a través del término agere, se centra en el énfasis que la filosofía posterior va a hacer en esta dimensión práctica sobre la que se funda un tipo de metafísica, que Agamben denomina una metafísica de la voluntad, "la vida entendida como energía e impulso creador", ${ }^{11}$ a lo que se refería Novalis cuando define la poesía en tanto que expresión artística por excelencia, como "uso voluntario, activo y productivo de nuestros órganos". ${ }^{12}$ Pasando por lugares tan distintos como la revitalización de la idea de trabajo en Marx o la filosofía de Nietzsche, Agamben insiste en vincular esta dimensión práctica con la propia naturaleza del hombre: "Que el hombre tenga sobre la tierra una condición productiva, significaría entonces que la condición de su habitar en el mundo es una condición práctica". ${ }^{13}$

Como era de esperar, este horizonte discursivo encuentra en la modernidad artística un terreno abonado, sobre todo en el paisaje de las vanguardias históricas y de forma ya explícita a partir de los años cincuenta con esta consolidación del performance como práctica artística y más tarde discursiva, una forma de creación que va a tener una influencia directa en otros ámbitos artísticos, como las artes visuales, las artes plásticas, la danza, el teatro o incluso la literatura. Es a partir de este amplio enfoque de estudio, desarrollado desde disciplinas y líneas de investigación distintas a lo largo del siglo XX, desde donde hay que entender, al menos desde un punto de vista histórico, la apertura del espacio universitario al arte como paradigma para discutir una forma práctica de investigación. Podríamos decir que Practice as Research es la etiqueta que se ha dado al efecto que este amplio movimiento cultural ha terminado teniendo en el ámbito institucional de la universidad dentro de la esfera anglosajona.

Si todo este recorrido histórico vale para algo es para ser más conscientes de un presente, que es el presente de hoy, en el que el espacio académico especializado, los denominados ciclos superiores, abre sus puertas a los lenguajes artísticos no como objeto de estudio sino como posibilidad para enfatizar una aproximación práctica -en el sentido en el que lo vamos a discutir a continuación - al hecho de la investigación; dicho en otras palabras: se recurre al arte como una forma de hacer que puede aportar una nueva dimensión en el modo de entender y difundir el conocimiento. Paradójicamente, este diálogo se produce por uno de sus puntos más conflictivos, el de la metodología de la investigación o las formas de las prácticas. No se trata aquí, por tanto, de un debate sobre espacios de conocimiento u objetos de estudio, sino sobre formas de saber que, como decíamos al comienzo, tiene algo que ver con las formas de poder.

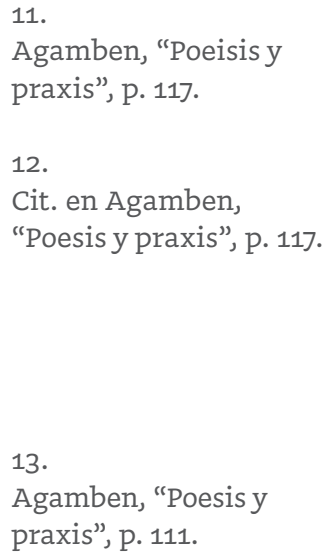


Dentro de este amplio panorama de revitalización de la idea de praxis, que en cierto modo ha sido la modernidad desde sus comienzos, hay una serie de referencias que se han convertido en canónicas, provenientes sobre todo de la antropología de lo sagrado, la sociología de la representación, la pragmática, la teoría posestructuralista o los estudios de género, y otras, con un carácter más filosófico, sin dejar de formar parte de este heterogéneo paisaje, han sido menos discutidas dentro de una bibliografía que ha pasado ya a ser clásica en los estudios performativos. ${ }^{14}$ Entre estas otras referencias merece la pena hacer un alto en el concepto de vita activa de Hannah Arendt, otro de los capítulos importantes de la historia del pensamiento del siglo XX directamente relacionado con la focalización en la idea de acción en relación a dos ámbitos frente a los cuales el concepto moderno de arte va a tener que definirse, aunque sea por exclusión, el del trabajo y la política.

En el comienzo de La condición humana Arendt ${ }^{15}$ diferencia tres tipos de prácticas que integran la vita activa: labor, trabajo y acción. La primera, la labor, tiene que ver con la condición natural del hombre, con las necesidades derivadas de su ser biológico; la segunda, el trabajo, con su condición mundana, con sus necesidades materiales, satisfechas artificialmente por medio de instrumentos; y la tercera, la acción, con su condición plural, con las necesidades derivadas de no ser el hombre, sino un hombre que vive junto a otros. Aunque estos tres tipos de prácticas están relacionados con la vida política del hombre, es esta última, la dimensión plural, la que se convierte en condición por la cual el hombre tiene vida política.

Arendt remonta el concepto de acción política al conflicto de Sócrates entre polis y filosofía. A juicio de Platón, su maestro encontró la muerte por someterse a la opinión pública, es decir, a la consideración de la polis, por tratar de buscar la verdad mediante la acción política, es decir, a través del diálogo con los otros. A partir de ahí la filosofía se retira de la polis para buscar la verdad en sí misma y se inicia una tradición marcada por la metafísica que ha dejado "lo social" como un ámbito atravesado por intereses espúreos y contingencias del momento, donde no habría oportunidad para la verdad, la autenticidad o la búsqueda de uno mismo al margen de intereses externos. De este modo, la vita contemplativa, que inicialmente había tenido un rango parejo a la vita activa, como las dos actividades desinteresadas que definían al hombre político, es decir al hombre libre (porque el trabajo, como las acciones derivadas de las necesidades biológicas, eran consideradas de una naturaleza servil y atendidas por los esclavos), pasa ya a la tradición latina con un rango superior. El hombre teórico y el hombre de acción inician caminos separados. Arendt defiende que cuando
14.

Marvin Carlson,

Performance. A critical introduction, London/ New York, Routledge, 1996; Erika FischerLichte y Christoph Wulf, eds., Theorien des Performativen, Berlin, Akademie Verlag, 2001, pp. 35-64 (núm. monográfico de la revista Paragrana, 10.1); Richard Schechner, Performance studies: an introduction, London/ New York, Routledge, 2002; Uwe Wirth, ed., Performanz. Zwischen Sprachphilosophie und Kulturwissenschaften. Frankfurt am Main, Suhrkamp, 2002; Erika Fischer-Lichte, Estética de lo performativo, Madrid, Abada, 2010.

15.

Hannah Arendt, La condición humana, Barcelona, Paidós, 1993. 
se amplía en la tradición latina el tipo de prácticas que caracterizan al hombre, no es porque la labor y el trabajo asciendan al nivel de la acción política, sino porque esta última se degrada al nivel de las anteriores, es decir, adquiere también una condición servil; sólo la actividad contemplativa o la reflexión teórica queda en un rango superior, libre de lo contingente, de lo que tiene sentido por responder a las necesidades inmediatas. Todavía para Aristóteles las dos acciones fundamentales del bios politikos que delimitan la esfera de los asuntos humanos, es decir, aquello que no está sujeto a una necesidad, acciones libres y desinteresadas, eran la praxis y el discurso. Aunque el pensamiento moderno ha tratado de revalorizar la praxis frente a la teoría (Marx, Nietzsche), Arendt insiste en que el marco teórico ha seguido siendo el mismo, lo que traducido a nuestra discusión, quiere decir que el conocimiento finalmente sigue siendo considerado como algo relativo no a una acción (política) sino a una actividad teórica (y aparentemente desinteresada) que hace ya siglos perdió su naturaleza de acción, es decir, su ser social como actuación junto a los otros, a pesar de que las tendencias actuales nos llevarían a pensar lo contrario.

Frente a las actividades productivas, o sea, el trabajo, la acción se realiza en sí misma, no en función de sus resultados, y tiene como característica esencial la revelación de un agente, es decir, de alguien que realiza ese acto. La acción nos habla de quien la hace. Como realización frente a los otros, la primera pregunta a la que responde es quién está actuando. Es por esto que como modelo de acción política Arendt se refiere a las prácticas artísticas que no dejan una obra como resultado, como por ejemplo una actuación escénica o musical, a las que Arendt recurre con frecuencia como punto de comparación, aunque el modelo central de análisis lo toma del discurso verbal en tanto que acción a través de la cual se revela quien habla y por correspondencia, a quien se dirige, poniendo de manifiesto la pluralidad como condición del ser.

La reivindicación de la acción en los medios intelectuales de izquierda dentro del contexto de las luchas sociales de los años sesenta es el antecedente más inmediato de una "actitud académica" que atravesó la universidad en aquel momento y que tres décadas después todavía está por entrar, aunque ahora el impulso viene desde dentro del propio sistema. El debate que aquí estamos planteando en torno a la investigación en artes recoge en cierto modo esta herencia social, aunque reformulada desde el espacio institucional.

La evolución de Tzvetan Todorov, director del Centro de Investigaciones sobre las Artes y el Lenguaje en el Centro Nacional de Investigaciones Científicas (CNRS) de París, resulta en este sentido relevante. Todorov llega a París a comienzos 
de los años sesenta, donde estudia con Barthes y se dedica a difundir el trabajo de los formalistas rusos. A partir de ahí se especializa en semiótica de la lengua, un campo en el que se convierte en una de las referencias internacionales. Lo interesante es su evolución a partir de los setenta y su distanciamiento con respecto al ámbito del estructuralismo, definido por Foucault en ese momento - recordemos - como condición del conocimiento. En la introducción a un libro todavía de los años setenta La conquista de América: el problema del otro, ${ }^{16}$ comienza advirtiendo que en la base de la semiótica lo que está es la relación con el otro, un enfoque que implica toda una actitud y una manera de mirar y que ha seguido desarrollando posteriormente. Ya en los noventa, en un libro titulado La vida en común, hace un repaso de este prejuicio anti-social en la tradicción occidental: "La sociabilidad es lo real; pero el ideal es la soledad, que es también la verdad profunda de nuestra naturaleza: ésta es la primera gran versión de la concepción individualista que subyace a nuestras representaciones de la vida humana”. ${ }^{17}$ En diálogo con la tradición filosófica y literaria se discute la necesidad de una actitud personal que pase por la relación con el otro: "La sociabilidad no es un accidente ni una contingencia; es la definicón misma de la condición humana", ${ }^{18}$ una condición que no puede ser entendida más que en términos de acción pública, esa misma actitud que llevó a Sócrates a la muerte y que marcó el giro metafísico del pensamiento occidental.

El estudio de las condiciones de trabajo en la sociedad posindustrial, donde la habilidad social y la capacidad de aprendizaje se han hecho imprescindibles, lleva a Virno a colocar la idea de acción, en el sentido en que lo utiliza también Arendt, en el centro de su discusión, aunque a diferencia de esta Virno parte de la tríada intelecto, trabajo y acción..$^{19}$ Es decir, ha sustituido la labor, aquellas prácticas que Arendt derivaba de la condición natural del hombre, por el intelecto. Esto no es casual, ya que Virno va a desarrollar la idea de intelecto a partir de lo que Marx denominaba el "intelecto general", donde se engloban las capacidades naturales que distinguen al hombre, como el habla, la memoria, el pensamiento, la razón, los afectos, las emociones o el deseo, que quedarían relacionadas con las labores "naturales" del hombre. Ahondando en la tendencia a la difuminación de los límites entre unos y otros tipos de práctica, ya apuntada por Arendt, Virno sitúa en el centro del actual sistema económico las potencias intelectuales. El trabajo habría adoptado las características de las prácticas políticas, que se habrían situado en la base de los diferentes tipos de prácticas. Como antecedente de este desplazamiento se cita la industria cultural, un terreno al que pertenece la univer-
16.

Tzvetan Todorov, La conquista de América: el problema del otro, Madrid, siglo XXI, 2010.

17.

Tzvetan Todorov, La vida en común. Ensayo de antropología general, Buenos Aires, Taurus, 1995, p. 19.

18

Todorov, La vida en común, p. 33.

19.

Paolo Virno, Gramática de la multitud. Para un análisis de las formas de vida contemporáneas, Madrid, Traficantes de Sueños, 2003. 
sidad y que habría ido ganando espacio a lo largo del siglo XX. Entre las características de este tipo de trabajo, presente ya en muchos otros sectores, como dirección de empresa, recursos humanos, márketing o finanzas, se destaca la actitud social del individuo, el denominado "intelecto general", es decir, la capacidad de hablar, de interactuar con los otros, de colaborar $\mathrm{y}$ vincularse, de crear afinidades y trabajar en grupos.

Entre las formas de colaboración diferencia aquellas donde la colaboración se produce entre los resultados del trabajo individual previamente realizado, de aquellas donde el trabajo mismo es resultado de una colaboración, es decir, la colaboración es condición previa a la acción. A partir de estos corrimientos la diferencia que establece Habermas entre acción instrumental y acción comunicativa quedaría igualmente difuminada, como la diferencia entre trabajo e interacción, porque la capacidad de comunicación, como la capacidad de colaboración e interacción, estarán en la base de la acción en el actual sistema de producción capitalista.

Lo más novedoso en el planteamiento de Virno es que, recurriendo al trabajo de George Simondon sobre procesos de individuación - una cuestión directamente relacionada con el fenómeno artístico一, sitúa estas potencias naturales como magma previo o espacio común sobre el que se construyen los individuos. Es decir, el individuo no es el punto de partida de la acción, sino producto de una potencia puesta en acto, o en otras palabras, de una acción que se está desarrollando. Primero es la acción (frente al otro), y luego el individuo. El yo se construye a través de la acción, y lo común no es un objetivo que hay que perseguir, sino una unidad previa; el objetivo es más bien la diferencia, la defensa de una pluralidad hecha pública, lo que Virno vincula con una democracia participativa, un planteamiento que tiene que ver con esa idea de proximidad que exponíamos al comienzo, en lugar de una democracia representativa.

Bajo la perspectiva de Virno, estos dos campos, teoría y práctica, o reflexión y acción, se terminan superponiendo al presentar el habla, siguiendo en la línea de Arendt, que a su vez se remonta, como hemos visto, hasta la filosofía griega, como la unidad mínima de acción. A diferencia del yo pienso, que Agamben colocaba en los comienzos de una subjetividad producto de una operación abstracta sobre la que se debía fundamentar el conocimiento, yo hablo se presenta como el performativo absoluto y se utiliza como modelo para el análisis del campo de la acción en la sociedad posindustrial, una acción política, en el sentido de Arendt, es decir, referida a un entorno social, llevada a cabo por una persona junto a otras, 
que abre una esfera pública y se realiza en sí misma, sin dejar un producto material como resultado. Al mismo tiempo, esta acción actualiza esa capacidad natural del intelecto que define al hombre, pone en juego una potencia adquirida que, como la lengua, se escenifica en cada ocurrencia concreta, en cada contexto específico de realización. Su representación admite la abstracción, pero no su realización física, aquí y ahora, frente a los demás.

Las cuestiones de método no son las más fáciles de resolver, a pesar de su apariencia subsidiaria como instrumentos para lograr unos objetivos. Chantal Maillard recuerda que Nietzsche tenía los métodos como el tipo de comprensión más costoso por ello más valioso, la comprensión de los cauces mismos del conocimiento, elevada por Maillard al rango de intuición, una intuición racional: la manera en la que se han de colocar los elementos para tener sentido. Este camino que lleva al conocimiento, en un momento en que se piensa antes el proceso que el producto o la potencia antes que el acto, pasa a ser en sí mismo objeto y resultado de la investigación, un camino que sólo en la medida en que sea recorrido, es decir, practicado, llegará a ser conocido. Por eso, concluye Maillard, "el método es algo más que una simple dirección o el trazo de una línea; el método es un hacer dentro del magma". ${ }^{20}$ Parafraseando la definición de Foucault, podemos acordar que el método es la conciencia formal del conocimiento científico.

Paul Feyerabend, una de las voces más críticas de la objetividad cientificista y el positivismo lógico, afirma que los científicos más relevantes han construido sus propios métodos, es decir, han sido a su vez filósofos de la ciencia, creadores de una forma de hacer - de pensar-. "La ciencia en su mejor aspecto -dice Feyerabend-, ${ }^{21}$ la ciencia en cuanto es practicada por nuestros grandes científicos, es una habilidad, o un arte, pero no una ciencia en el sentido de una empresa "racional" que obedece a estándares inalterables de la razón y que usa conceptos bien definidos, estables, "objetivos" y por esto también independientes de la práctica". En su libro más conocido, Tratado contra el método, y en estudios posteriores nacidos a la luz de la polémica a la que dio lugar el primero, defiende la ciencia como una práctica ligada a un contexto preciso, por ello la dificultad de importar metodologías que pudieron servir en unos momentos y lugares, pero que no van a servir en situaciones distintas. Como corrector de esa tendencia a la abstracción, sospechosamente desinteresada y antipolítica, que domina la investigación, aboga por unas prácticas más democráticas, por una ciencia - o un arte, podríamos añadir- que nazca como respuesta a un contexto material y no teórico.
20

Chantal Maillard, Filosofía en los días críticos. Diarios 1996-1998, Valencia, Pre-Textos, 2001, p. 52.

21.

Paul Feyerabend, Adiós a la razón, Madrid, Tecnos, 1984, p. 32. 
Esta tradición crítica que - como vemos - tiene un largo recorrido, parece que comienza a filtrarse en los espacios oficiales destinados a la producción de conocimiento - después de haber conquistado los espacios de la producción económica-, resultado sin duda de la necesidad por parte de estos de abrirse a las dinámicas sociales del momento, es decir, de estar al día, de seguir presentándose como un servicio público eficaz. Es desde este planteamiento desde que el que se produce la inserción de las artes dentro del espacio superior de enseñanza; no resultaría, por tanto, sensato tratar de encontrarles métodos y formas de actuación predeterminados que las legitimen como formas de investigación, cuando lo que se están buscando son lugares para cuestionar lo que ya parece legitimado, un tipo de conocimiento sostenido a través de una forma que la autoriza. Lo más coherente, siguiendo con este enfoque del conocimiento como práctica, será que esas formas se definan a partir del mismo hacer artístico, pero sí parece útil tener en cuenta como base de ese hacer este panorama histórico en el que debajo de movimientos aparentemente desinteresados se esconden discursos de legitimación de los diferentes tipos de práctica.

Los métodos en ciencias serían comparables a los géneros en arte, y si hace tiempo que el artista tiene que ser a su vez creador de las propias reglas del juego sobre las que va a construir la obra, en un momento en que los géneros ya no valen para legitimar un tipo u otro de práctica, con más razón se habrán de construir igualmente los canales que transformen su hacer en forma de conocimiento. O dicho con los términos de Virno, en una sociedad posindustrial que obliga a una continua actualización de la capacidad de aprendizaje, así como de otras capacidades intelectuales, el artista ha de ser necesariamente, de una u otra forma, también un pensador, en el sentido en que lo proponía el director vasco Óskar Gómez en Cerebro magullado 2. King Kong Fire, sobre un texto de Anton Reixa: "El pensamiento viaja al interior del cuerpo", pero un cuerpo, por escénico, necesariamente puesto en relación a otro y situado junto a otros, un cuerpo-pensamiento hecho público. Es desde esta posición activa de reflexión que el arte se deja ver, desde su mismo proceso de creación y aún antes, como una forma de duda y, por tanto, de posibilidad de conocimiento puesto en escena, es decir, consciente y con vocación de abrirse a un espacio público. Es desde esta actitud capaz de convertir una actividad personal en un debate social que las formas de actuar en arte pueden ser rentabilizadas en aquellos otros ámbitos con disposición a entrar en contacto con este tipo de prácticas creativas. En ese lugar del ensayo abierto, de la tentativa frustrada, de la duda y del proceso como forma 
de colaboración, reinventado cada vez sobre las posibilidades que ofrece ese magma indiferenciado que Marx denominó "intelecto general", y en el que radica la potencia social del individuo, ciencia y arte vuelven a encontrarse para repensar las formas de conocimiento, entendidas como formas de estar, exponerse y relacionarse.

Este pensamiento de una forma en proceso, o dándole la vuelta a la ecuación, esta forma que piensa - retomando la formulación de Godard del ensayo en cine, un género creado también como respuesta a este conflicto entre arte y cienciano es ya resultado de una representación, sino la representación de un aquí y un ahora puesto en escena como forma en proceso, como actualización de una potencia (de pensar) expresada a través de una forma convertida en acción, que es el punto de partida de un modo de hacer en público, de hacer arte o de hacer ciencia, de hacer política en el sentido en el que lo exponía Arendt, no por desinteresado sino por transindividual, como diría Simondon, de hacer yo junto a los otros.

Si interrumpiera aquí este artículo, quedaría resonando un tono injustificadamente triunfalista acerca del momento que parece abrirse en torno a las relaciones entre arte e investigación, o la posibilidad de transformar el modo de entender el conocimiento. Sin embargo, el arte es el último convidado en llegar a la mesa. Su capacidad para quedar como un adorno que acompañe las transformaciones sociales, cuando ya todo está hecho, es un peligro constante de las prácticas artísticas. Visto a grandes rasgos, así fue a partir del siglo XVIII, cuando se consolida una manera de entender la ciencia y el conocimiento basado en la subjetividad a cambio de cederle a esta un campo propio de juego, el arte. Ahora nuevamente prolifera el término "creativo" y toda una constelación de ideas en torno a él como estrategia para legitimar las prácticas que organizan el sistema económico global y por ende los modos de hacer poder. Adoptar estas formas, que tienen que ver con el dinamismo, la hibridez, los procesos, la interacción, la proximidad, la apertura a lo otro, no supone una postura frente al sistema, sino apenas un estar dentro del juego; no es un punto de llegada, sino la condición para estar, o dicho en otros términos, no es una metodología, sino los materiales para construirla. De esto nos advierten Negri y Hardt cuando exponen las transformaciones que llevaron de lo que ellos llaman Imperio al imperialismo, ${ }^{22}$ como dos modos de funcionamiento del capital, poniendo de manifiesto hasta qué punto todo este vocabulario está en el centro, no sólo de los movimientos culturales críticos, sino de los sistemas económicos y las formas de poder. Por eso argumentan que por sí sola la movilidad, los intercambios y la indeterminación, como las esencias o las identidades, no
22.

Michael Hardt y Antonio Negri, Imperio, Buenos Aires, Paidós, 2002. 
nos hará más libre, la cuestión está en los "regímenes de producción". Una posición que tiene que ver con lo que defiende Feyerabend o lo que propone Michel de Certeau como criterio de lo científico: "Un discurso mantendrá por tanto una marca de cientificidad al hacer explícitas las condiciones y las reglas de su producción, y de entrada las relaciones a partir de las cuales nace". ${ }^{23}$

Por eso, lo dicho hasta aquí, no hay que entenderlo como un punto de llegada, una metodología en sí mismo, sino como la posibilidad de un punto de partida, materiales sobre los que construir las formas de actuar, que tienen que ver con estas potencias del hombre, con su capacidad de crear, de pensar, de recordar, de tener afectos y emociones, de desarrollar relaciones. Sobre este magma informe se desarrolla una posibilidad científica o artística que es en primer lugar un ejercicio de presente donde se hace visible una situación de comunicación y producción al mismo tiempo que está latente en todo proceso de investigación como de creación. Sacar a la luz, hacer pública esa situación pragmática de un yo hablando a un tú, aunque quede - necesariamente - reinventada, implica construir una metodología sobre un presente concreto que configura a su vez una economía, una forma de plantear el poder, un modo de producción de relaciones, afectos, redes e identidades, por inmaterial no menos real.
23

Michel de Certeau, La invención de lo cotidiano I, p. 52 


\section{CURRÍCULUM ABREVIADO}

Óscar Cornago es investigador en el Centro de Humanidades y Ciencias Sociales del Consejo Superior de Investigaciones Científicas de Madrid. Su trabajo se ha especializado en historia del teatro contemporáneo y teoría de los medios. Actualmente dirige el proyecto "Imaginarios sociales en las culturas de la globalización: lo público y lo privado. Documentación y análisis de la creación escénica en Iberoamérica (2000-2010)". Entre sus libros se encuentran La vanguardia teatral en España (1965-1975): del ritual al juego, Pensar la teatralidad y Resistir en la era de los medios: estrategias performativas en literatura, teatro, cine y televisión. Forma parte de ARTEA y es coordinador del Archivo Virtual de las Artes Escénicas (http://artesescenicas.org). Ha estudiado y documentado la obra de directores contemporáneos en España y Latinoamérica en libros como Políticas de la palabra, Éticas del cuerpo y Acercamientos a lo real. 